\title{
Mode profiling of THz fibers with dynamic aperture near-field imaging
}

Stecher, Matthias; Dürrschmidt, Stefan F.; Nielsen, Kristian; Stefani, Alessio; Rasmussen, Henrik K.; Jepsen, Peter Uhd; Bang, Ole; Town, Graham E.; Koch, Martin

Published in:

2011 36th International Conference on Infrared, Millimeter and Terahertz Waves (IRMMW-THz)

Link to article, DOI:

10.1109/irmmw-THz.2011.6105088

Publication date:

2011

Link back to DTU Orbit

Citation (APA):

Stecher, M., Dürrschmidt, S. F., Nielsen, K., Stefani, A., Rasmussen, H. K., Jepsen, P. U., Bang, O., Town, G. E., \& Koch, M. (2011). Mode profiling of THz fibers with dynamic aperture near-field imaging. In 2011 36th International Conference on Infrared, Millimeter and Terahertz Waves (IRMMW-THz) IEEE. International Conference on Infrared, Millimeter and Terahertz Waves https://doi.org/10.1109/irmmw-THz.2011.6105088

\section{General rights}

Copyright and moral rights for the publications made accessible in the public portal are retained by the authors and/or other copyright owners and it is a condition of accessing publications that users recognise and abide by the legal requirements associated with these rights.

- Users may download and print one copy of any publication from the public portal for the purpose of private study or research.

- You may not further distribute the material or use it for any profit-making activity or commercial gain

- You may freely distribute the URL identifying the publication in the public portal 


\title{
Mode profiling of THz fibers with dynamic aperture near-field imaging
}

\author{
Matthias Stecher ${ }^{1}$, Stefan F. Dürrschmidt ${ }^{1}$, Kristian Nielsen ${ }^{2}$, Alessio Stefani ${ }^{2}$, Henrik K. Rasmussen ${ }^{3}$, Peter \\ Uhd Jepsen², Ole Bang ${ }^{2}$, Graham E. Town ${ }^{4}$, and Martin Koch ${ }^{1}$ \\ ${ }^{1}$ Philipps-Universität Marburg, Department of Physics, Germany \\ ${ }^{2}$ DTU- Fotonik - Department of Photonics Engineering, Technical University of Denmark, Denmark \\ ${ }^{3}$ DTU- Mechanics - Department of Mechanical Engineering, Technical University of Denmark, Denmark \\ ${ }^{34}$ Department of Electronic Engineering, Macquarie University, NSW, Australia
}

\begin{abstract}
We present terahertz near-field mode profiling of different polymer THz fibers. Images with a resolution below the THz wavelength show the fundamental mode profile and higher order modes appearing at higher frequencies.
\end{abstract}

\section{INTRODUCTION AND BACKGROUND}

Along with the fast and steady increasing advances in terahertz (THz) technology over the last decade, there has been a broad development in $\mathrm{THz}$ waveguiding schemes, inspired from their counterparts in the RF and optical domains. Various polymers were tested for their absorption and dispersion characteristics. Jördens et al. [1] showed, for example, that polyethylene wires can act as $\mathrm{THz}$ waveguides and splitters. Nielsen et al. [2] presented a non-dispersive, $\mathrm{THz}$ photonic crystal fiber (PCF) based on TOPAS $^{\circledR}$, a cyclic olefin copolymer. Other porous or microstructured fiber have been proposed [3, 4] and their respective mode profiles have been analyzed by different methods.

In this paper we demonstrate a fast and accurate way to measure mode profiles with sub-wavelength resolution in custom made $\mathrm{THz}$ waveguides. Several different TOPAS THz fibers, fabricated at DTU Fotonik were investigated. In particular we show results obtained on triangular structured TOPAS PCFs with varying pitch. The cross section of such a fiber with a four ring lattice can be seen in Figure 2(a).

\section{EXPERIMENTAL SETUP AND RESULTS}

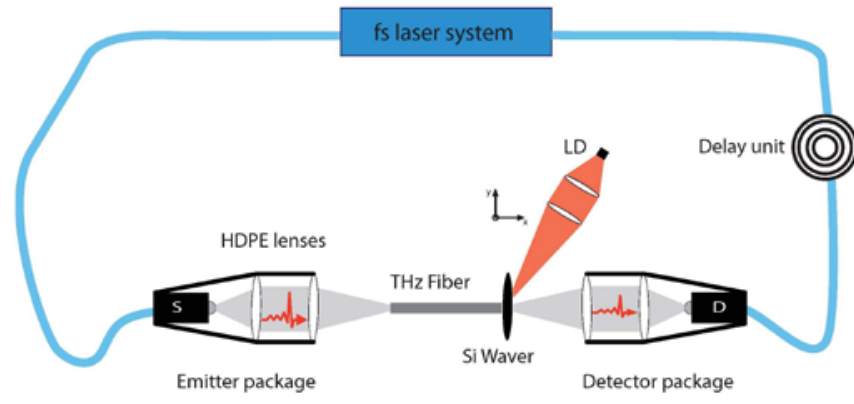

Fig. 1 Schematic of the THz near-field setup

The setup used is a standard THz Time Domain spectrometer (TDS) driven by a femtosecond fiber laser emitting 85 fs pulses

at $1550 \mathrm{~nm}$. The THz beam was focused into the polymer fibers under inspection and detected by a photoconductive antenna. A one end of the fibers and was locally excited by a continuous wave $808 \mathrm{~nm}$ laser diode. Our setup is similar to that introduced by Zhang's group in 2000 [5]. Yet, for simplicity we use a continuous wave laser diode, which is chopped and focused to a spot size of approx. $200 \mu \mathrm{m}$. By scanning the optical excitation across the HR-Si wafer near-field images of $101 \times 101$ pixels are recorded, acquiring a full $\mathrm{THz}$ wave form for each pixel. A schematic of the near-field TDS setup is depicted in Figure 1.

a)

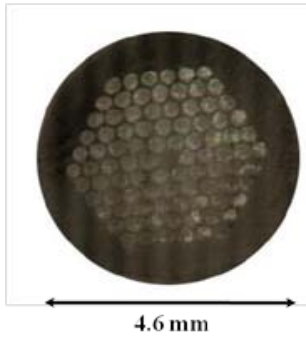

c)

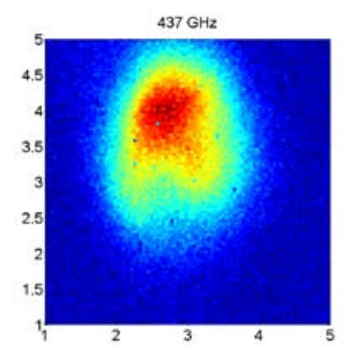

Fig. 2 (Cross-section (a) and near-field images of a four ring triangular structured Topas fiber: peak-to-peak $\mathrm{THz}$ pulse amplitude (b); Mode intensities at $437 \mathrm{GHz}$ (c) and $710 \mathrm{GHz}$ (d)

Raster scanning the laser beam across the silicon wafer makes it possible to locally modulate the amplitude and phase of the $\mathrm{THz}$ pulse. The maximum pulse amplitude distribution, containing all frequency components, for the four ring structured fiber is shown in Figure 2(b). Taking the full waveforms for each pixel under consideration one can obtain field distributions for single frequencies of interest. A mode profile measured at the end of a $5 \mathrm{~cm}$ long fiber for -frequencies of 437 and $710 \mathrm{GHz}$ is presented in Figs. 2(c) and 2(d), respectively. The PCF has an average hole diameter of $\mathrm{d}=$ 
$285 \mu \mathrm{m}$ and an average pitch of $\Lambda=370 \mu \mathrm{m}$, giving a relative hole diameter of $\mathrm{d} / \Lambda=0.77$, which means that it becomes multi-moded at high frequencies [2, 6]. For a relative hole size of $\mathrm{d} / \Lambda=0.77$ the PCF becomes multi-moded for wavelengths below $\lambda / \Lambda \approx 1.1$ [6], corresponding to frequencies above $\mathbb{E}$ $\mathrm{c} /(1.1 \Lambda)=737 \mathrm{GHz}$. The high-resolution images clearly show the transition to a higher order mode with three maxima at $710 \mathrm{GHz}$, which is reasonably close to the theoretically predicted $737 \mathrm{GHz}$.

For comparison a fiber designed to restrict higher order modes from being guided was also measured. The fiber was $4 \mathrm{~mm}$ in diameter and had a triangular lattice with a lower relative hole size of 0.44 (hole diameter $245 \mu \mathrm{m}$ ), which makes it single-moded for all frequencies [6].. A picture of the fiber's cross-section is shown in Figure 3a. It can be seen that the fiber offers a better mode confinement and that no higher order modes are present at $751 \mathrm{GHz}$.

a)

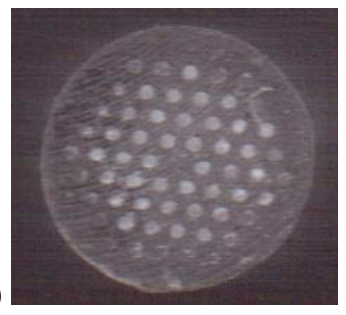

b)

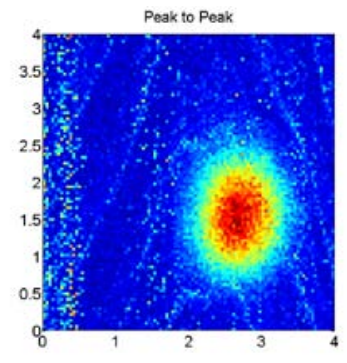

c)

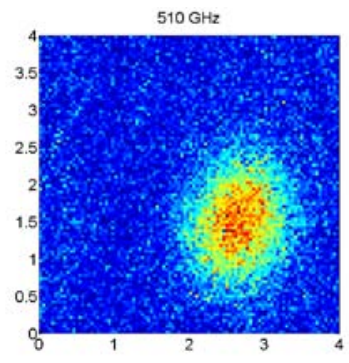

Fig. 3 (a) Cross-section (a) and near-field images of a triangular structured TOPAS fiber: maximum $\mathrm{THz}$ pulse amplitude (b); Mode distribution at $510 \mathrm{GHz}$ (c) and $751 \mathrm{GHz}$ (d)

The versatile method might also be used for analyzing mode profiles of other waveguide structures, like parallel plate or ribbon waveguides. By reducing the focal spot size one can reach even higher spatial resolutions, but there will be a trade-off between spatial resolution and interaction with the passing $\mathrm{THz}$ field. So depending on the available $\mathrm{THz}$ power there is an optimum optical excited spot size to have sufficient signal to noise ratio for the task at hand.

\section{SUMMARY}

In conclusion, we have demonstrated a powerful tool to analyze $\mathrm{THz}$ fibers and waveguides by terahertz time domain spectroscopy. Modulating the optical excitation allows sub-wavelength resolution for the $\mathrm{THz}$ mode profile imaging and the verification of cut-off frequencies in these waveguides. Adjusting the optical excitation power and the focal spot size enables higher resolution, but also lowers the interaction between the induced modulation and the electric $\mathrm{THz}$ field. Mode profile images of different $\mathrm{THz}$ fiber waveguides have been presented and analyzed.

\section{REFERENCES}

[1] C. Jördens, K. Chee, I. Al-Naib, I. Pupeza, S. Peik, G. Wenke, and M. Koch, "Dielectric Fibres for Low-Loss Transmission of Millimetre Waves and its Application in Couplers and Splitters," Journal of Infrared, Millimeter and Terahertz Waves 31, 214-220.

[2] K. Nielsen, H. K. Rasmussen, A. J. Adam, P. C. Planken, O. Bang, and P. U. Jepsen, "Bendable, low-loss Topas fibers for the terahertz frequency range," Opt. Express 17, 8592-8601 (2009).

[3] M. Rozé, B. Ung, A. Mazhorova, M. Walther, and M. Skorobogatiy, "Suspended core subwavelength fibers: towards practical designs for low-loss terahertz guidance," Opt. Express 19, 9127-9138.

[4] J. Anthony, R. Leonhardt, A. Argyros, and M. C. J. Large, "Characterization of a microstructured Zeonex terahertz fiber," J. Opt. Soc. Am. B 28, 1013-1018.

[5] Q. Chen, Z. Jiang, G. X. Xu, and X. C. Zhang, "Near-field terahertz imaging with a dynamic aperture," Opt. Lett. 25, 1122-1124 (2000).

[6] M. Koshiba and K. Saitoh, Applicability of classical optical fiber theories to holey fibers, Opt. Lett. 29, 1739-1741 (2004). 